\title{
The MHC and body odors: arbitrary effects caused by shifts of mean pleasantness
}

The main conclusions of the study by issue of Nature Genetics differ from those of most previous studies of the major histocompatibility complex (MHC) and mate or odor preference in any animal ${ }^{2}$. It is therefore important to understand what may have caused these differences. In this study ${ }^{1}, 49$ smellers (who were handled as independent replicates in the statistical analysis) chose the most and the least preferred odor out of only six body odors provided by donors of different ethnic background. This is a kind of pseudoreplication $^{3,4}$ that can easily create misleading results. If, for example, only one donor with rather rare MHC alleles tended to smell slightly less pleasant than others because of something that is not correlated to the MHC (such as odor intensity ${ }^{5}$ or an illness), this would produce a bias in the analysis towards the conclusion that MHC-similar types smelled better. Such arbitrary shifts of mean pleasantness can cause all sorts of incorrect results (Fig. 1). By contrast, an analysis based on withindonor comparisons ${ }^{5,6}$ would not be changed by such constant shifts of pleasantness scores.

These arbitrary effects depend on the number of allele matches between each donor and the smellers. In an outbred group of non-kin (such as a typical sample of college students ${ }^{5,6}$ ), identical haplotypes are rare and donors are not expected to differ, on average, in the number of allele matches to the maternally and the paternally inherited genotypes of the smellers. The smellers in the study by Jacob et al. ${ }^{1}$ were members of an inbred group that has only a few haplotypes. This increases the risk that, in a given sample, MHC alleles will not be equally distributed to maternally and paternally inherited genotypes. Indeed, the MHC alleles in this case happened to be distributed non-randomly (Fig. 2). This fact, combined with the aforementioned arbitrary effects, can cause all sorts of outcomes that only appear to be caused differentially by maternal and paternal MHC types. Therefore, the conclusions that women have paternally inherited odor preferences ${ }^{1}$ and that they prefer odors of MHC-similar donors ${ }^{1}$ are not justified.

\section{Claus Wedekind}

Institute of Cell, Animal and Population Biology, University of Edinburgh, Edinburgh EH9 3JT, UK (e-mail: c.wedekind@ed.ac.uk).
1. Jacob, S., McClintock, M.K., Zelano, B. \& Ober, C. Nature Genet. 30, 175-179 (2002).
2. Potts, W.K. Nature Genet. 30, 130-131 (2002)
3. Hurlbert, S.H. Ecol. Monogr. 54, 187-211 (1984).
4. Ramirez, C.C., Fuentes-Contreras, E., Rodriguez, L.C. \& Niemeyer, H.M. J. Chem. Ecol. 26, 1423-1431 (2000).
5. Wedekind, C. \& Füri, S. Proc. R. Soc. Lond. B 264 , 1471-1479 (1997)
6. Wedekind, C., Seebeck, T., Bettens, F. \& Paepke, A.J. MHC-dependent mate preferences in humans. Proc. R. Soc. Lond. B 260, 245-249 (1995).

\begin{abstract}
Fig. 1 How pseudoreplication can lead to erroneous conclusions if factors that are not correlated with the MHC affect odor pleasantness.

The data are taken from a study $^{5}$ comparable to that of Jacob et al. ${ }^{1}$. If the mean pleasantness scores

of the six odors were shifted as shown, for example, by the open bars, analyzing the data by the method of Jacob et al. ${ }^{1}$ would lead to the conclusion that MHC-similar types smelled better (Wilcoxon paired-sign test, $N=95, P=0.018$, two-tailed). If the scores were shifted as shown in the grey or black bars, this analysis would lead to the opposite conclusion that MHC-dissimilar types smelled better (both $P<0.01$ ). Asterisks show the mean actual observations ${ }^{5}$. Values are mean \pm s.e.m.
\end{abstract}

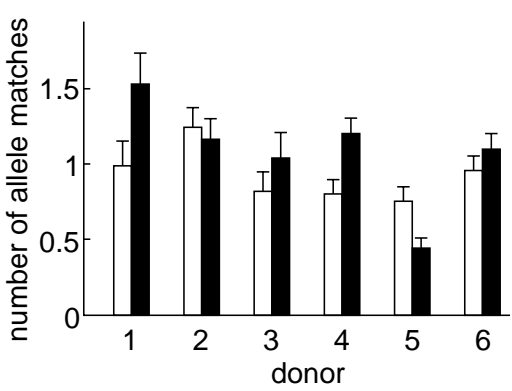

Fig. 2 The number of matches between the MHC of the six odor donors and maternally (open bars) or paternally (filled bars) inherited MHC alleles of the smellers (multivariate repeatedmeasures ANOVA, interaction between odor donor and maternally or paternally inherited alleles, $F_{5,44}=6.21, P=0.0002$ ). The data are taken from Fig. 1 in ref. 1. Values are mean \pm s.e.m.

\section{In reply-}

$T^{\mathrm{n}}$ his comments on our paper ${ }^{1}$, Wedekind raises two separate issues. First, he mentions the problem of 'pseudoreplication', although he does not indicate how he believes this is relevant in our case. As defined by Hurlbert ${ }^{3}$ (who seems to have coined the term as used in this context), pseudoreplication refers to the treatment of multiple measurements on a single experimental unit as though they came from separate independent units, leading to an overestimate of the amount of information in the data. For example, consider two different studies of chemotherapy and tumor growth in mice. In the first, one tumor is created in the right hind leg of each of 12 mice, and they are then treated. In the second, tumors are created in both hind legs of 6 mice (2 tumors per mouse). Both studies evaluate 12 tumors, but the first provides more information because it includes twice as many independent units of analysis. In the second study, the two tumors in each mouse are pseudoreplicates, as there is the possibility for within-mouse correlation in the outcome. 